\title{
Cultural Obstacles in Transnational Trade Union Cooperation in Europe'
}

\section{Bengt Larsson ${ }^{2}$}

Professor, Department of Sociology and Work Science, University of Gothenburg, Sweden

\begin{abstract}
This article focuses on cultural difficulties in trade union cooperation and transnationalization in Europe. The aim is to understand cultural differences that are seen as obstacles to cooperation by trade union representatives with transnational work experience from the ETUC and ETUFs. The theoretical inspiration for this work comes from the sociological variant of neo-institutionalism and organization theory, as well as from existing approaches in industrial relations and trade union research. The empirical analysis is based on 38 interviews with 46 representatives from trade unions from nine European countries. The findings point to problems arising because of language and translation issues, differences in cultural conceptions, values and everyday practices, and differences in trade union traditions, ideologies and identities.
\end{abstract}

\section{KEYWORDS}

Industrial relations / trade unions / culture / cooperation / social dialogue

\section{Introduction}

gainst the background of the Europeanization of financial, products, services and labor markets, and setbacks in trade union power on national arenas in Europe, transnational trade union cooperation is of great importance for the development of conditions for workers in European countries (Baccaro \& Howell 2017; Erne 2008; Kelly 2015; Lehndorff et al. 2017). In addition, such cooperation is needed in order for trade unions to contribute to the multilevel governance of the EU through European-level social dialogue with employers, as encouraged by the European Commission (Müller 2016; Rhodes 2015; Welz 2015).

Existing research indicates that cultural divergences play a role in union cooperation in Europe. That is, studies of European trade union organizations and social dialogues show that not only trade union ideologies but also values, identities, expectations, and language may both facilitate and hinder cooperation (Ciampiani \& Tilly 2017; Gumbrell-McCormick \& Hyman 2013: 172ff.; Larsson 2012; Pernicka \& Glassner 2014). In addition, research on European Works Councils (EWCs) has found that linguistic skills, identity, and national and organizational rootedness and expectations may create problems for cooperation (Hann et al. 2017; Stirling \& Tully 2004; Whittall et al. 2007).

However, with some exceptions (e.g., Barbier 2013: 65ff.; Black 2005; Klemm \& Weyand 2009; Klemm et al. 2011; Pernicka \& Glassner 2014), the cultural element is

\footnotetext{
${ }^{1}$ You can find this text and its DOI at https://tidsskrift.dk/njwls/index.

${ }^{2}$ Corresponding author: Bengt Larsson, Department of Sociology and Work Science, University of Gothenburg, Box 720, 40530 Gothenburg, Sweden. E-mail: bengt.larsson@socav.gu.se.
} 
seldom explicitly theorized or focused on in studies of comparative industrial relations and transnational trade union cooperation. Meardi (2011: 336) notes that cultural factors are often used as 'emergency' variables that account for the 'unexplained residua' of other explanations (cf. Barbier 2013: 65ff.). This is unfortunate if Barbier is correct in claiming that 'national boundaries and cultural diversity are the fundamental reasons for the limited extension of solidarity in Europe' (Barbier 2013: 65). Of course, shared identities and norms do exist (Pernicka \& Glassner 2014), as do solidarity actions on the European level, but as shown by Gajewska (2009: 145) trade unions from different countries often understand and 'frame' the issues differently, and their interpretation 'is contingent on the ideological profile of the trade union'.

This article studies cultural difficulties in trade union cooperation and transnationalization in Europe. This is a problem quite well researched on the company level in EWCs (e.g., Hann et al. 2017; Klemm \& Weyand 2009; Klemm et al. 2011; Stirling \& Tully 2004; Whittall et al. 2007). However, there seems to be less research focusing explicitly on cultural differences in sector-level cooperation between trade unions, in their organizational networking and in connection to the work in European trade union federations (ETUFs) and the European Trade Union Confederation (ETUC). The aim of this article is thus to contribute to our understanding of this by studying what cultural difficulties are seen as obstacles to cooperation by top-level and centrally placed trade union officials.

The article begins with a theoretical discussion of the concept of culture and possible approaches to culture in industrial relations and trade union research. This is followed by a description of the material and methods, and the empirical analysis, which was based on an interview study with trade union representatives from nine European countries. The article ends with a short summary of the main results and some conclusions on studying culture and cultural differences in European trade union cooperation.

\section{Culture and trade union research}

Culture is a contested concept, and in much research, it is not defined but rather taken for granted (Smith 2016). The sociological conceptualization of culture generally refers to 'the knowledge, beliefs, expectations, values, practices, and material objects by means of which we craft meaningful experiences' (McLean 2017: 1). Thus, culture is not a well-defined 'single thing' but rather a set of conceptions, practices and artefacts that are imbued with ideas and meanings. As implied by 'we' in McLean's quotation, culture is also something that is collectively shared by a group of individuals, consisting of 'patterns of thinking, feeling and acting' (Hofstede et al. 2010: 5). Focusing on culture from this approach is, thus, to acknowledge both political-normative values such as those expressed in trade union traditions and ideologies - such as whether trade unions are communist, social democratic, or have a religious base, or whether they are more conflict- or consensus-oriented toward employer organizations (cf. Hyman 2001a). But also to acknowledge cultural-cognitively based conceptions, repertoires, identities and practices of a more 'taken for granted' character, based on how things are usually done (Cullinane 2014; Strandgaard Pedersen \& Dobbin 2006; cf. Klemm \& Weyand 2009; Lamont \& Thévenot 2000).

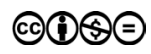




\section{Studying trade union cultures and cultural differences}

A reasonable starting point in discussing trade unions and culture is Hyman's (2001a) study. This departs from culturally oriented questions such as 'how far are traditions and inherited assumptions a resource, how far a constraint?' and 'to what extent can labor movements escape from their past and redefine their purpose and identity' (Hyman 2001a: ix [italics added]). Hyman elaborates on how trade union identities and ideologies have emerged and became institutionalized into different models and traditions across Europe. The cultural aspect of this is that the 'identities embraced by [...] unions [...] have shaped the interest with which they identify [...] the agenda they pursue, and the type of power resources which they cultivate and apply' (Hyman 2001a: 1 [italics added]).

Thus, cultural factors are from this approach not only consequences of structural relations (e.g., interest conflicts between labor and capital, the laws defining their space for bargaining, or their power resources), but are also formative elements of trade unions' interests, agendas and power resources-and even of the extension of solidarity across countries (cf. Klemm \& Weyand 2009). To give this an extra touch of sociological neo-institutionalism, one might add that identities and ideological orientations of trade unions may also be grounded in conceptions and practices that are taken for granted in the wider cultural context: 'Organizations arise and grow permeated with norms, values, and meanings drawn from broader society' (Suddaby et al. 2010: 1235; cf. Strandgaard Pedersen \& Dobbin 2006: 898). This is also in line with Hyman's emphasis of the importance of 'ideas, beliefs, social norms and indeed language in shaping industrial relations' (Hyman 2004: 270).

Even though the constitutive elements of culture are important for trade union solidarity and cooperation across Europe (Pernicka et al. 2017), there are also cultural difficulties in transnational trade union cooperation (Klemm \& Weyand 2009; Whittall et al. 2007). Language borders may hamper direct trade union cooperation, but language also shapes the understanding of industrial relations. The basic concepts used in communication are grounded in different meaning contexts; as a result, 'political words do not travel as easily as one might imagine' (Barbier 2013: 19). Language may also be important for trade unions in actively elaborating strategies through 'framing processes' (Gajewska 2009). Gajewska's study of transnational solidarity also emphasizes the relation between trade union identities and national cultures on the one hand, and trade unions' interests and solidarity on the other hand.

However, the idea is not to suggest that trade union culture, identity, and ideology are all that matter, since previous research shows that cultural factors are seen as less of a problem for trade union co-operation than institutional differences; for example, differences in labor market policies and regulation, or the power resources of unions and employers (Larsson 2012). Nor does it seem like a good idea to turn to a nationalist or essentialist approach to culture (cf. Barbier 2013: 107ff.; Meardi 2011). Instead, inspiration is taken from the multilevel governance approach, so that culture is approached as multilayered and changing, and interwoven with structural factors in existing industrial relations institutions.

Empirically, a multilevel approach toward culture and cultural difference implies that we may study the existences of cultural communities at different levels. At the European level, it is possible to discuss the existence of European cultural values (Inglehart \& Welzel 2005), or that of a European political/industrial relations or trade union culture (cf. Pernicka \& Glassner 2014). However, there are also regional and national value differences 
and industrial relations and trade union cultures (Andersson \& Thörnqvist 2007; Barbier 2013; Hofstede et al. 2010; Hyman 2001a; Klemm et al. 2011). In turn, these are internally heterogeneous, as there is much variation relating to groupings such as generation, social classes, gender, etc., and between varying organizational cultures and taken-forgranted practices (Strandgaard Pedersen \& Dobbin 2006). This approach emphasizes that cultural homogeneity and divergence only exist relationally, with internal heterogeneity, tension, and change at every cultural level (Hyman 2001a; Klemm et al. 2011).

\section{Methodological approach and material}

There are varying approaches to studying culture and cultural differences. One quite objectivist approach involves comparative value surveys exploring the value dimensions on which the social groupings in regions, countries and organizations differ (Hofstede et al. 2010; Inglehart \& Welzel 2005). A second, rather structuralist approach analyzes culture as an underlying structure of concepts, codes, grammars, narratives, or symbols (Alexander 2003; cf. Lamont \& Thévenot 2000). Both of these approaches may be valuable for understanding cultural differences as obstacles to trade union cooperation in Europe: the former in explaining the surrounding value structures that set the context for trade unions (e.g., Black 2005); and the latter in understanding how established concepts, ideas, and cultural repertoires delimit mutual understanding and cooperation (e.g., Barbier 2013).

However, to understand the specific difficulties that cultural differences create for European trade union cooperation, it is also possible to move closer to the actors, through targeted surveys, observations, or as in this case interviews with the actors (e.g., Gajewska 2009; Pernicka et al. 2017; Klemm et al. 2011; Larsson 2012, 2017; Whittall et al. 2007). These are more subjectivist and interpretative approaches that aim to understand the perspectives and experiences of the actors themselves. Such approaches obviously involve the risk that accounts are based on (and reproduce) existing cultural stereotypes. It therefore does not help in establishing objective cultural differences, but only experienced differences that affect cooperation. When studying the latter, it does however not matter much whether respondents' views are correct or biased, as they would affect co-operation in any case, in line with the Thomas theorem: 'If men define situations as real, they are real in their consequences' (Thomas \& Thomas 1928: 572). Nevertheless, for analysis to be as unbiased as possible, a prerequisite is that experiences from different regions in Europe need to be taken into account.

This study is based on 38 interviews with 46 trade union officials with experience in union cooperation both within ETUFs and/or the ETUC and in direct bi- or multilateral cooperation. Nine interviews took place in 2012, and the rest in 2015-2016. To recruit respondents, we contacted top-level management and international secretariats. Initially, we targeted unions in five sectors (mining and metals, construction, transportation, healthcare, and banking and finance) in five countries (DE, SE, IT, UK, CZ). Because of nonresponses and recommendations, we extended our requests to more countries, and representatives from peak-level confederations when told that they were the ones with experience in European-level work.

Because of difficulties in recruiting, there is some variation in the number of interviews finally made in different regimes and sectors: The Nordic region is represented by seven interviews with Swedish (SE) officials and one from a joint Nordic union (Nord); 
the central western region by eight interviews with German (DE) and two with Belgian (BE) officials; the southern region by five Italian (IT) and three Spanish (ES) officials; the central eastern region by three interviews each with officials from the Czech Republic (CZ), and Hungary (HU), two from Latvia (LV) and one from Lithuania (LT); and the British Isles are represented by three interviews with officials from the UK (UK). Regarding sectors, 10 interviews were conducted with representatives of confederations; the rest were from trade unions in healthcare (9), construction (6), metal (5), banking and finance (5), and transportation (3).

Although the interviewees had different positions, they all had experience working in ETUFs, the ETUC and with social dialogues, and many also had experience with direct bi- and multilateral cooperation in Europe: 15 of our respondents had a top-level position (i.e., general secretary, president, or vice-president); 12 had a position as heading or coordinating a secretariat; six were international secretaries; and the remaining 13 had advisory or strategic positions. In many cases, their experiences went beyond their current position, as some had a history in their or other organizations, and some had additional assignments in a regional, European, or international organization. The interviews were mainly conducted in English, with some in Swedish and German. The researchers conducting the interviews were highly proficient in these languages and, with only three exceptions, we found that the respondents had a good working English in the interviews performed in English. In two of those cases, we used a professional interpreter, and in one case, another official from the trade union took the role of interpreting. However, there may still be issues regarding cultural and linguistic misinterpretation, and we want to caution the reader about this (cf. Barbier 2013; Hyman 2004).

The interviews were semi-structured and lasted 1-2 hours each. The ones conducted in 2012 (1-9) had a slightly narrower focus on cooperation in the context of the postLaval situation and minimum wages, and those conducted in 2015-2016 (10-38) had a broader focus on cooperation more generally. We asked about cooperation bilaterally and through involvement in the work of ETUFs and the EUTC: what partners they have; how they cooperate and on what issues; what obstacles or difficulties they meet in this co-operation; and what they believe to be important issues for the future. The theme focused on in this analysis was introduced by a general question of what obstacles and difficulties exist in transnational trade union cooperation. Not all informants mentioned cultural aspects, but when they did, we asked some follow-up questions to elaborate.

The interviews were transcribed verbatim and analyzed in Atlas.ti. The analysis of the interviews was thematic: the first cycle coding of 'difficulties in trade union cooperation' was coded in the second cycle in separate forms of difficulties, and culture was an emergent theme in this work. Three main subthemes were subsequently developed relating to language-related difficulties, difficulties based on cultural values and practices, and difficulties in relation to normative values and trade union ideology. The quotations in the text are slightly edited to increase readability.

\section{Language and translation}

As noted, language and conceptual differences are important aspects of cultural variation in Europe. Language differences and a lack of language skills have been discussed as obstacles to trade union co-operation on the company level in EWCs (e.g., Whittall 
et al. 2007). According to our interviews, they are also a problem within the ETUC and ETUFs. In particular, Central Eastern European respondents stated that the language barrier is 'strong', 'essential', 'huge', or even 'the major obstacle'. A few interviewees from the more dominant German- and English-language areas saw less of a problem, because good translations and interpretation exist, whereas others acknowledged difficulties particularly in meetings with no interpretation: some participants would not 'understand half of it' and some stay silent. Thus, 'the language barrier is still an enormous problem' (6 DE; $23 \mathrm{UK}$ ).

The number of languages that documents are translated into varies, as does the number of interpreters. At ETUC and ETUF congresses, there is funding for interpretation in up to six languages. At committee meetings, there are slightly fewer, whereas working groups and seminars are generally in English only. Those lacking language skills thus have to forgo attending meetings or put in major resources because 'every trade union that participates has [to bring] their own interpreter with them' (27 CZ; cf. Henning 2015b). There is also the additional cost of translating documents before and after meetings:

We need to make a lot of effort to translate the material. [... In] ETUC and [our ETUF], Italian is not a formal, official language. That means that we need to translate several materials. And this is part of our expenses for the international job. (36 IT)

In fact, the linguistic barrier is significant even in regional networks. Some southern networks is said to include countries from Portugal to Israel, and some Central Eastern European groups often use English. In European meetings in particular, English is used in everyday work in committees and working groups, and many 'switch to speaking some kind of joint bad English' (14 SE). However, the use of international English creates problems because of the loss of local idiom and meanings. Similar problems also arise when using interpreters and translation: 'even if the interpreters are very good, very skilled and very professional, it's always mediation' (34 IT). This distorting effect muddles communication since statements lose their meaning when being translated 'from one language to another, to another, to another' (30 HU). Nevertheless, there are difficulties in establishing English as the joint language, as some members do not have the skills and others are unwilling:

[Our ETUF] has repeatedly said this: let's decide once and for all that we are using English. Let us do that. We save a tremendous amount of time and a lot of money, both on translation and interpretation. All of it! But it doesn't work. The French never go along with it. Spaniards, very, very bad. And now that we have the entire [Eastern European] side! [But] they're better, I may say, in English. (13 SE)

There is also a generational aspect of language skills. Some of the older generation say that 'we will never be so confident that we can use [English] fluently' (31 HU). Many express the view that English skills will continue to improve as the younger generation steps up. However, there are obstacles in recruiting highly educated young people, particularly in eastern and southern Europe where unions are hard-pressed and better jobs seem more appealing.

Both comprehension and the possibility to influence joint decisions are undermined because of language. Some stay silent or have little influence because of their difficulty to 
express themselves: 'If [...] I have a chance of speaking in Czech then my voice is stronger than [... in] English' (29 CZ). Moreover, there is the risk that the organization selects representatives on the basis of their language skills rather than on their expertise (23 UK; cf. Landgraf 2015), which also affects the ability to influence decisions:

If we have two or three people who are capable of speaking in English, the same people have to be competent in various themes and specific subjects, and it's very hard to do that at a good level. [...] We have to multitask, [....] and during the meetings, it's very hard to come out with an argument or a competent opinion about things. (21 LV)

Gajewska (2009: 117ff.) emphasizes that communication is not only used in deliberation but also to build contacts, relationships, and trust. The absence of a common language makes this difficult, because 'small talk is always difficult' (22 DE). Yet, small talk is hugely important, because 'that's where you develop trains of thought' (11 SE). Exchanging views beforehand is important in order to find common positions, and to develop new ideas and concrete partnerships. Such linguistic opportunity structures ultimately influence the partners with whom trade union respondents cooperate. A British trade unionist explained why they did not have much cooperation with Mediterranean countries:

I think it's a language thing actually. Because, the Nordic representatives speak good English. We have several German speakers within [our TU]. So, it's easier to communicate. [...] It's that personal relationship and that talking in-between $[\ldots]$ when you're sitting having your coffee people tend to group within their languages, because you can chat. [....] And the real business doesn't get done in the exchanges around the table. The real business gets done in the meeting beforehand or over lunch. (24 UK)

Some interviewees stressed that the absence of language skills has nothing to do with culture, that the difficulties are 'not cultural, but language differences' (27 CZ). However, such a distinction between language as medium and culture as meaning is not straightforward. Terms and concepts in a language are embedded in and relate to a cognitive (and often normative) content and a common world of reference (Barbier 2013: 109). Consequently, it is difficult to cooperate when similar concepts have different meanings:

The Nordic countries [have] a different understanding of what 'austerity' means, what 'crisis' in the public sector means. [...] You need to build a common vocabulary [...] to understand what the others are saying. And if the words are different, like 'privatization' or 'public sector' or what the meaning is of 'autonomous', 'independent'. [...] This is the major obstacle. (36 IT)

These problems are accentuated when the documents are sent home, because not everyone in the organization understands the difference in connotation from their own context. For instance, it is well known that even such general concepts as 'industrial relations' and 'social partners' have different connotations across Europe (cf. Hyman 2004). As a result, translations of central documents may create some problems:

The hardest question is this: how to translate the documents? [...] [Translations] can become so immensely inaccurate, and then there can be misunderstandings in the documents 
that are produced. [...] Particularly this problem with confusion of tongues, that it carries different meanings, can be the most difficult one to manage. [...] And then there may follow a kind of hostility sometimes. (15 SE)

\section{Cultural values and practices}

Not only language but also differences in cultural values, conceptions, and practices may create obstacles for cooperation: 'This is almost a greater obstacle, I would say [...], than that the trades unions have different views on the issues' (10 Nord). It is not sufficient to speak the same language, as understanding is not just about 'what they're saying, but also understanding the cultural situation they're in' (23 UK). Consequently, 'Culture remains a big difficulty because persons $[. .$.$] arrive from their national experi-$ ence’ (36 IT).

According to some respondents, these cultural differences should not be exaggerated because they can be bridged. As discussed by Hofstede et al. (2010: 384ff.), there is often a process of acculturation following an initial cultural shock. But even that requires quite some effort:

We have different cultures; that's the basic point. So it's very important to try to understand [...] your own culture [...], but to be open to others' cultures as well; in Europe in this case. It's not easy at the very beginning. But if you participate in many meetings, over many years, you can do it. (38 IT)

The basic cultural divergences highlighted are those between the North and the South, and the East and the West. A British respondent stated that their relations with French colleagues were difficult: 'that's partly about language, but it's also about the traditions and the way they do things' (23 UK). On a similar note, a Nordic representative said that Nordics find some representatives 'impossible to co-operate with. They have a different tradition and, like, you have to butter them up' (10 Nord). In contrast, the internal homogeneity among the Nordic countries is strong, because they 'live in the same cultural world' and 'see things the same way' (13 and 11 SE). Naturally, such differences are viewed differently from the South, but they are also acknowledged:

It is easier for us [Italians] to have co-operation with the Mediterranean countries, I'm talking about the Spanish and French [...], because we have more or less the same culture, and it's easier for us to have good relations. [...] When we talk with our colleagues from Scandinavia, it's complicated [for them] to understand our problems, because, you know, they are very far from us. (37 IT)

East-West differences are by some discussed from the viewpoint that some Central Eastern European societies are 'hierocracies' and 'post-communist' rather than 'democratic' in their culture. This is acknowledged by respondents from both Western and some Central Eastern European countries (cf. Henning 2015a; Meardi 2011):

Cultural differences are large, because some European countries are post-communist, and they have to learn all things about democracy. For all the democratic countries, that is not 
a problem. They have lived in a democratic society for the past 80 years. But our cultural difference makes our position difficult. (31 HU)

These North-South and East-West cultural differences that were expressed are of course very categorical. For example, one respondent from Latvia did not want to include the Baltic States as part of the Central Eastern European culture. On the contrary, they were said to have 'a lot in common in legislation, in our approach, in our, let's say cultural mentality' with the Nordic countries ( $32 \mathrm{LV}$ ). Indeed, the chosen level of comparison decides what is seen as homogeneous or different. Just as in the case of the Baltics being somewhat in-between Central Eastern European and Nordic cultures, the homogeneity of the latter disappears when no external comparison is made. In practice, such seemingly homogeneous regions also struggle with internal cultural heterogeneity, so much so that a joint Nordic confederation brought in consultants to increase the level of understanding:

The Danish [...] are very straightforward [...]. If you are quiet, you have nothing to say, from a Danish perspective. While in Finland, it may well be that you are talking in a different way, you have a bit longer pauses and so on, but if you sit in a meeting you are expected to be asked by the chairman of the meeting about what to do. And if you are not asked, you leave the meeting feeling trampled on. $(10$ Nord)

In comparison with the cultural variation that exists at the European level, these Nordic differences are relatively small. Similarly, general European differences shrink in comparison with other continents, thus making European cultural homogeneity visible, whereas 'other nations, Asian nations, Muslim or African nations, have other cultures' (35 HU).

The cultural differences discussed above are not only differences in values and conceptions, but also in traditions and trivial everyday practices: 'You have slightly different views on what is expected in social situations, and you express yourself in very different ways' (10 Nord). This can involve everything from how delegates from various countries relate to the starting times of meetings, whether they come early or late, if they find it acceptable or not to leave meetings to talk on the phone, to how much they talk in meetings and how they interact socially. Small differences in everyday practices and cultural repertoires also affect the ability for 'small talk' and for light-hearted socializing, and thereby affect how quickly the parties will be able to cooperate:

I would not underestimate the power of that ability, to have lunch or a cup of coffee with somebody, and in a few sentences come to an agreement. And being able to do that because you can talk about other things, football, walking or, you know. (24 UK)

In addition, such cultural differences affect the internal democratic processes in joint organizations. One example is the variation between the more 'talkative' southern European delegates and the more 'taciturn' Nordics highlighted in a study of speech patterns at meetings of the executive committee of ETUC (Furåker and Lovén Seldén, 2016). Because the Nordic countries generally have strong coordination through their joint organizations, their position is already negotiated with less room and need to mark a unique position: 'So we make a few statements to explain our position, and then the others get to talk' (16 SE). This is said to lead to some confusion, and even irritation from 
other representatives, who in contrast 'must express the ideas, values and agenda of their organizations', irrespective of others voicing a similar line of argument (10 Nord). This difference is also seen as a general divide in cultures and practices between the North and the South:

The Nordic countries are used to negotiating, the Germans are, and we [British] are. [...] It is culture! And it is easier for us to do business with the Nordics and the Germans because they understand, or we have a common interest in doing a deal. Whereas it seems to me, and I'm aware that I'm stereotyping culturally, the French and the Spanish and the Greeks in particular, come to those meetings to make a point, to make a speech. (24 UK)

Cultural differences are also important for how the member organizations perceive joint decisions and their content, and their legitimacy and binding power. '[Others] do not have the same strong formalistic approach to democracy that we have here in the Nordic region', said one Nordic representative with reference to the consensus-oriented decision form (10 Nord). There is seldom any voting that takes place, except in congresses; the process is rather one of consensus-seeking, followed by an attempt to spell out the decision in an understandable summary:

We have our model in Sweden, how to do it. [Then there's] the Germanic model, you have the question 'who is for, who is against, who abstains?' We don't do it like that here. This must be learned. If you don't, you immediately kick up a row. And why? Because then they will not understand what they have decided [...] So, clearly, cultural differences makes it difficult. And that's why it is necessary to understand these cultural differences. [...] I have seen those who have failed with that. The consequence was crazy decisions, if any decisions at all. (13 SE)

The consequences of cultural differences can thus be quite serious. They affect not only whether decisions are perceived as legitimate but also how their content is understood and how well they are implemented, that is, whether there is a cultural expectation that joint decisions will be implemented to the letter or whether they are taken more lightly.

\section{Trade union ideologies and identities}

Some respondents see general cultural divergences as less important than differences in trade union ideology. As is well known, the different roots and traditions have created a diversity of ideas regarding what trade unions are, and what their activities and goals should be (Gumbrell-McCormick \& Hyman 2013: 1ff.; 152ff.; Henning 2015a; Hyman 2001a). This was also acknowledged by some respondents:

The history of the labor movement in each country is different. So, on general central items, we have a common position, but sometimes it's difficult to arrive at that position because of the diversity in the real basis of every union within each country. (2 ES)

The deepest divide in trade union culture is said to be between consensus-oriented and conflict-oriented traditions. These are not neatly enclosed in countries or regions, but the 
main divide discussed by the respondents is that between northern and southern Europe (cf. Henning 2015b). Swedish representatives describe their relations to employers as 'co-operative', with a strong emphasis on both members and their companies. This is contrasted with a more 'universal' approach connected to an explicit political and radical stance in the South, which is 'far more confrontational' (16 SE), involving more 'campaign organizations' that do not take place at the negotiating table but 'go in the streets and shout' (10 Nord). Such divergence in 'visions' and 'points of view' is also acknowledged by some southern representatives: 'in the Nordic countries, you have more of a co-operation model. [...] In the South, we approach our relationship as a struggle' (38 and 34 IT):

There is a clear division North-South. We mobilize the workers at the social and political level; we have general strikes, mass demonstrations in the streets. The Nordic unions have collective bargaining at the sectoral level or national level. [...] It is, therefore, not easy to establish one [common] way of trade union action at the European level. (1 ES)

Theoretically, this difference may be conceptualized by two 'ideal types'. In one, unions are cartels representing the interests of its members in bargaining. In the other, they are political movements representing workers in general (Hyman 2001a; Lovén Seldén 2014). The cartel strategy is to organize members locally, whereas the unions that are in a political movement create strength through mobilization and protests. The former involves 'long-term work in the workplace to gain members', whereas the latter is less about 'numerical strength' and more about 'having your loyal crowd' (11 SE).

Such divergences in identity and ideology, and national political culture, create problems. Whereas the Nordics are trying to work 'with the employers, also at the European level' and try 'to be a bit more constructive' and give 'alternative proposals' instead of 'just saying no' (11 SE), they experience that others find them a bit 'wimpish', 'not passionate enough', or 'wooden' when preferring dialogue over conflict and campaign. But this difficulty in understanding runs both ways:

To work jointly with the employer as we do in the North. [...] That is not in the mindset of our colleagues further south. They think that is a hole in the head. They think that we are sitting in the lap of the employer. [...] There is a general lack of understanding, I think. And many times, also an unwillingness to even discuss at all. Of course, I might feel the same reluctance, because I do not want their system. (14 SE)

This is acknowledged by some representatives from the South who think the Nordics have a limited view of solidarity and are 'less European' in their attitude (1 ES; cf. Lovén Seldén 2014). One example is the long-standing differences in approach toward the ETUC (e.g., Ciampiani \& Tilly 2017), concerning whether the organization should be used offensively to create 'strong compromises' and 'fight for all' and for 'more integration within the EU', or more defensively to 'protect affiliates only', or as a 'lobby' to safeguard national traditions (1 and 2 ES; 37 IT):

[ETUC] is a compromise between different visions of trade unionism in Europe. For us, the Mediterranean, it remains a confederation, because we have this system in which the confederation is a general actor in collective bargaining, playing the main role. In the Nordic vision, in Germany, in the UK and so on, it is more a lobby organization. (36 IT) 
From the Nordic perspective, the conflictual and campaigning strategies of some southern unions also create problems on the European level in relation to employer organizations: they become skeptical and 'quite hostile', which makes it difficult to have a dialogue (16 SE): 'But when we present solutions that may also help them, I think you can notice a change in attitude. [t...] That we are actually explicitly invited' (10 Nord).

In addition to this North-South dimension, there is also discussion of an East-West dimension. Some Central Eastern European unions are said to have different approaches and cultures, and 'a completely different view on trade unions' (10 Nord). In part, this is because they might have their roots in the former communist or post-Soviet system, and in part, because some of them have very strong connections to political parties (17 $\mathrm{SE} ; 30 \mathrm{DE})$. This otherness is acknowledged to some extent by some Central Eastern European respondents who still 'have union leaders from Soviet times' (32 LV), who acknowledge that their national political culture is still more 'hierocratic' and 'postcommunist' than 'democratic' ( 30 and $31 \mathrm{HU}$ ), or who still find themselves 'stuck with the stigma' of being government organizations $(28 \mathrm{CZ})$.

These simple North-South and East-West distinctions are of course very schematic. First, many trade unions are not that close to the theoretical ideal types, for example, Belgian unions state that they 'are somewhere in the middle' between German and Latin traditions $(5 \mathrm{BE})$. Second, there are different trade union cultures and ideologies within North-South and East-West regions and countries; some are more homogeneous, some more fragmented: 'There is much more variety in the group of the new member states [...] it is not a homogeneous group like the old 15 member states' (6 DE). There is also a national divergence that blurs the simplistic distinctions between North-South and East-West; for example, Belgium is seen to have some 'very radical Catholic trade unions', whereas some Italian unions are found to be just as 'utilitarian' as the Nordics find themselves to be (17 SE; cf. Jouan \& Tilly 2017). However, such national heterogeneity or fragmentation is also seen as an obstacle, most obviously for unions from regions with a homogeneous trade union culture:

Some countries in southern Europe and the former Eastern Bloc countries, [...] they may have 17 trade unions [in the sector], and some are super conservative, and some are super Catholic, and some are super communist [...] You hardly understand how they get it together at all [...], there are a lot of small ones that first must fight each other. (14 SE)

This situation affects the willingness of others to cooperate. It is easier to do so with countries that have only one or two trade unions in your sector, than with a large number of competing unions, 'especially if you have hostility between different organizations' (6 DE). When homogeneous or large unions meet with such fragmented foreign friends, the problem arises that you may have 'the role of moderator between them, which we don't like' (7 DE). This difference between homogeneous and fragmented cultures and its effects on the possibility to have influence is also acknowledged by respondents from the South:

I've seen that the Scandinavian unions, they are all together when they are abroad. [...] Sometimes we [Italian unions] are one against the other. Because our culture is to show that we are the best. So, when we go [to meetings] we are not three together, we are single unions, and we lose power because of this. But it's culture. (37 IT) 


\section{Discussion and conclusions}

It has been said that there has been too little of an explicit focus on the issue of culture in studies on comparative industrial relations and trade unions (cf. Meardi 2011; Barbier 2013). This study has suggested that we should acknowledge the theoretical and empirical analyses that already exist, and may even strengthen them further with inspiration from the sociological variant of neo-institutionalism into industrial relations research (Lamont \& Thévenot 2000; Strandgaard Pedersen \& Dobbin 2006; cf. Cullinane 2014). This article is a modest attempt to show that such an approach fits with some of the existing theoretical reasoning within the field of industrial relations and trade union research that has focused on cultural elements (e.g., Barbier 2013; Gajewska 2009; Hyman 2001a; 2004; Klemm et al. 2011; Klemm \& Weyand 2009; Pernicka \& Glassner 2014; Whittall et al. 2007). By focusing on the experiences of differences in normative and cultural-cognitive repertoires, identities, and informal practices, we can obtain knowledge about the cultural difficulties in transnational trade union cooperation. This empirical study was an attempt to contribute to this by analyzing what, and why, cultural differences hamper cooperation within work in the ETUC and ETUFs according to centrally placed trade and top-level union officials.

As stated above, Barbier (2013: 65) claims that national boundaries and cultural diversity are 'fundamental reasons for the limited extension of solidarity in Europe'. However, that claim may need to be qualified, as previous studies show that cultural factors are not seen by trade unions themselves as the most important obstacles to trade union cooperation in Europe (Larsson 2012; 2017). Nor are cultural similarities seen as the most important factors for successful cooperation. More important as obstacles and for successful cooperation are factors relating to: financial and network resources; priorities; and differences in national labor market policies and regulations.

Even so, it is obvious from the present and previous studies that cultural differences are obstacles of importance. If this is the general contribution of this study, the specific contribution is providing a more detailed analysis of how cultural differences can make cooperation difficult. In this, these results confirm that some of the obstacles that exist on the company level in the work of EWCs also exist in trade union cooperation in the ETUC and ETUFs, and in direct organizational networking between high-level officials (e.g., Hann et al. 2017; Klemm \& Weyand 2009; Klemm et al. 2011; Stirling \& Tully 2004; Whittall et al. 2007).

First, language issues create multiple problems. The lack of language skills undermines not only direct interaction and mutual understanding, but also has effects on trust and network building, and the possibility to take part and influence decisions, as well as on the understanding, legitimacy and implementation of such. These problems cannot be reduced to financial issues regarding translation costs or staffing, because terms and concepts refer to a contextually embedded cognitive and normative understanding. However, resources matter. It seems obvious that language differences are related to and reproduce power differences in cooperation, by influencing who can participate and make their voices heard, how preparatory texts and outcomes are understood at home, and who may interact with whom on an informal basis between meetings.

Second, these language issues are reinforced by the differences experienced in $\mathrm{cul}$ tural values and practices, although they are more difficult to pin down, because they 
deal more generally with differences in national (or regional) culture and traditions. Such general differences in values and everyday practices not only hamper common understanding and network and trust building, but also seem to lead to misunderstandings, minor irritations, and even to some hostility between trade unionists who have difficulties understanding why others behave differently from them.

Third, differences in ideology and identity are experienced, in relation both to the level of national (or regional) values and practices, and to the organizational level. When approached from a very high level of abstraction, these were discussed mainly in terms of differences between a stronger negotiation, partnership, and member orientation in northern Europe and more of a confrontation and mobilizing politicized tradition in southern Europe. In addition, East-West differences in values and practices are said to create some difficulties. However, when discussed in more detail, this simple regional categorization disappears because there is another axis between countries with more homogeneous trade union cultures and more fragmented ones. Such differences generate problems of finding common interests and strategies, because of differing ideas and conceptions of what trade unions are, what they should do, and how.

These results should of course not be exaggerated since much co-operation exists and much is achieved through transnational trade union cooperation in Europe. As discussed by Pernicka and Glassner (2014), a joint European culture of trade unionism might be emerging through the ongoing European-level co-operation and dialogue. Not all our interviewees emphasized cultural difficulties, but some obviously did. In this connection, it may be of importance to note that studying obstacles to cooperationwhether cultural or structural-does not always imply that one is 'falsely assessing the co-operation potential' of trade union solidarity (Gajewska 2009: 15) or departing from a 'pessimist' approach (Seeliger 2019). On the contrary, the aim may be to increase the possibilities for participating parties to transcend such obstacles through facilitating a better understanding of them (Barbier 2013). This is also in line with the conclusions drawn by Klemm and Weyand (2009: 276-277) in their research on the cultural aspects of transnational co-operation in the context of EWCs: 'Becoming aware of different historical and cultural experiences and of different forms of self- and other-perception is an important step on the way to building a European labour identity'.

\section{Acknowledgments}

This research was funded by the Swedish Foundation for Humanities and Social Sciences (Riksbankens Jubileumsfond), Grant P13-0776:1. The data were collected with help from the project members: Bengt Furåker, Mattias Bengtsson, and Kristina Lovén Seldén. The author wants to thank the anonymous reviewers for constructive comments.

\section{References}

Alexander, J. (2003). The Meanings of Social Life. A Cultural Sociology, Oxford: Oxford UP. Andersson, M. \& Thörnqvist, C. (2007). Regional clusters of communication: between national and European identities, in Whittall M., Knudsen H. and Huijgen F. (eds) Towards a European Labour Identity, London: Routledge. 
Baccaro, L. \& Howell, C. (2017). Trajectories of Neoliberal Transformation. European Industrial Relations since the 1970s, Cambridge: Cambridge University Press.

Barbier, J. C. (2013). The Road to Social Europe. A Contemporary Approach to Political Cultures and Diversity in Europe, London: Routledge.

Black, B. (2005). Comparative industrial relations theory: The role of national culture, International Journal of Humans Resource Management 16(7): 1137-1158.

Ciampiani, A. \& Tilly, P. (eds) (2017). National Trade Unions and the ETUC: A History of Unity and Diversity, Brussels: ETUI.

Cullinane, N. (2014). Institutions and the industrial relations tradition. In: Wilkinson, A., Wood, G. \& Deeg, R. (eds) The Oxford Handbook of Employment Relations: Comparative employment Systems, Oxford: Oxford UP.

Erne, R. (2008). European Unions. Labor's Quest for a Transnational Democracy, Ithaca: Cornell University Press.

Furåker, B. \& Lovén Seldén, K. (2016). Patterns of speech activity at ETUC Executive Committee meetings, 2005-2012, European Journal of Industrial Relations 22(1): 57-71.

Gajewska, K. (2009). Transnational Labour Solidarity. Mechanisms of Commitment to Cooperation within the European Trade Union Movement, London: Routledge.

Gumbrell-McCormick, R. \& Hyman, R. (2013). Trade Unions in Western Europe. Hard Times, Hard Choices, Oxford: Oxford UP.

Hann, D., Hauptmeier, M. \& Waddington, J. (2017). European Works Councils after two decades, European Journal of Industrial Relations, DOI: https://doi.org/10.1177/0959680117715190.

Henning, K. (2015a). Trade unions and industrial relations in the EU member states of eastern enlargement. In: Landgraf, C. \& Pleines, H. (eds) Interest Representation and Europeanization of Trade Unions from EU Member States of the Eastern Enlargement, Stuttgart: Ibidem.

Henning, K. (2015b). Not dominant but existent. Involvement of trade unions from EU member states of eastern enlargement in European Trade Union Federations. In: Landgraf, C. \& Pleines, H. (eds) Interest Representation and Europeanization of Trade Unions from EU Member States of the Eastern Enlargement, Stuttgart: Ibidem.

Hofstede, G., Hofstede, G. J. \& Minkov, M. (2010). Cultures and Organizations. Intercultural Cooperation and Its Importance for Survival, New York: McGraw Hill.

Hyman, R. (2001a). Understanding European Trade Unionism. Between Market, Class and Society, London: Sage.

Hyman, R. (2001b). Trade union research and cross-national comparison, European Journal of Industrial Relations 7(2): 203-232.

Hyman, R. (2004). Is industrial relations theory always ethnocentric? In: Kaufman, B. E. (ed) Theoretical Perspectives on Work and the Employment Relationship, Champaign, IL: Industrial Relations Research Association.

Inglehart, R. \& Welzel, C. (2005). Modernization, Cultural Change, and Democracy, Cambridge: Cambridge UP.

Jouan, Q. \& Tilly, P. (2017). The Belgian trade union organisations: National divisions and common European action. In Ciampiani, A. \& Tilly, P. (eds) National Trade Unions and the ETUC: A History of Unity and Diversity, Brussels: ETUI.

Kelly, J. (2015). Trade union membership and power in comparative perspective, The Economic and Labour Relations Review 26(4): 526-544.

Klemm, M. \& Weyand, J. (2009). Communication and solidarity in cross-cultural employee relations, in Hertwig, M., Pries, L. \& Rampeltshammer, L. (eds) European Works Councils in Complementary Perspectives, Brussels: ETUI.

Klemm, M., Kraetsch, C. \& Weyand, J. (2011). Solidarität in der europäischen betrieblichen Mitbestimmung als theoretische Herausforderung - Ein kultursoziologischer Lösungsvorschlag, Industrielle Beziehungen 18(4): 292-331. 
Lamont, M. \& Thévenot, L. (2000). Introduction: Toward a renewed comparative cultural sociology. In Lamont, M. \& Thévenot, L. (eds) Rethinking Comparative Cultural Sociology. Repertoires of Evaluation in France and the United States, Cambridge: Cambridge UP.

Landgraf, C. (2015). EU-level activities of trade unions from the new EU member states. In: Landgraf, C. \& Pleines, H. (eds) Interest Representation and Europeanization of Trade Unions from EU Member States of the Eastern Enlargement, Stuttgart: Ibidem.

Larsson, B. (2012). Obstacles to transnational trade union cooperation in Europe: Results from a European survey, Industrial Relations Journal 43(2): 152-170.

Larsson, B. (2017). Cultural borders as obstacles to trade union cooperation. In: Andren M. (eds) Cultural Borders in Europe, Gothenburg: CERGU.

Lehndorff, S., Dribbusch, H., and Schulten, T. (2017). European trade unions in a time of crises - an overview. In S. Lehndorff, H. Dribbusch, and T. Schulten (eds.) Rough Waters. European Trade Unions in a Time of Crises, Brussels: ETUI AISBL.

Lovén Seldén, K. (2014). Laval and trade union cooperation: Views on the mobilizing potential of the case, The International Journal of Comparative Labour Law and Industrial Relations 30(1): 87-104.

McLean, P. (2017). Culture in Networks, Cambridge: Polity.

Meardi, G. (2011). Understanding trade union cultures, Industrielle Beziehungen 18(4): $336-345$.

Müller, T. (2016). The ETUC's coordination of collective bargaining in times of crisis, CLR News, 2: 6-12.

Pernicka, S. \& Glassner, V. (2014). Transnational trade union strategies towards European wage policy: A neo-institutional framework, European Journal of Industrial Relations, 20(4): 317-334.

Pernicka, S., Glassner, V., Dittmar, N., Mrozowicki, A. \& Maciejewska, M. (2017). When does solidarity end? Transnational labour cooperation during and after the crisis: The GM/Opel case revisited, Economic and Industrial Democracy, 38(3): 375-399.

Rhodes, M. (2015). Employment policy: Between efficacy and experimentation, In H. Wallace, M. A. Pollack, and A. R. Young (eds.), Policy Making in the European Union, Oxford: Oxford University Press.

Seeliger, M. (2019). Trade Unions in the Course of European Integration. The Social Construction of Organized Interests, London: Routledge.

Smith, C. (2016). The conceptual incoherence of 'culture' in American sociology, American Sociologist 47(4): 388-415.

Scott, R. (2008). Institutions and Organisations, Thousand Oaks: Sage.

Stirling, J. \& Tully, B. (2004). Power, process and practice: Communications in European Works Councils, European Journal of Industrial Relations 10(1): 73-89.

Strandgaard Pedersen, J. \& Dobbin, F. (2006). In search of identity and legitimation. Bridging organizational culture and neoinstitutionalism, American Behavioral Scientist, 49(7): 897-907.

Suddaby, R., Elsbach, K. D., Greenwood, R., Meyer, J. W. \& Zilber, T. B. (2010). Organizations and their institutional environments: Bringing meaning, values, and culture back in, Academy of Management Journal 53(6): 1234-1240.

Thomas, W. I. \& Thomas, D. S. (1928). The Child in America. Behavior Problems and Programs, New York: Knopf.

Welz, C. (2015). From Val Duchesse to Riga: How to relaunch social dialogue?, Foundation Focus, 17: 3-5.

Whittall, M., Knudsen, H. \& Huijgen, F. (eds) (2007). Towards a European Labour Identity, London: Routledge. 